\title{
Can Fluctuations in the Consumption- Wealth Ratio Help to Predict Exchange Rates?
}

\author{
Jorge Selaive* y Vicente Tuesta** \\ *Banco Central de Chile \\ **Banco Central de Reserva del Perú
}

\author{
DT. $\mathrm{N}^{\circ}$. 2005-002 \\ Serie de Documentos de Trabajo \\ Working Paper series \\ Enero 2005
}
Los puntos de vista expresados en este documento de trabajo corresponden a los de los autores y no reflejan necesariamente la posición del Banco Central de Reserva del Perú.

The views expressed in this paper are those of the authors and do not reflect necessarily the position of the Central Reserve Bank of Peru. 


\title{
"Can Fluctuations in the Consumption-Wealth Ratio Help to Predict Exchange Rates? "*
}

\author{
Jorge Selaive ${ }^{\dagger}$ \\ Vicente Tuesta R. $\ddagger$ \\ Central Bank of Chile \\ Central Reserve Bank of Perú
}

First version, november 2003

This version, january 2005

\begin{abstract}
It is well documented that macroeconomic fundamentals are little help in predicting changes in nominal exchange rates compared to the predictions made by a simple random walk. Lettau and Ludvigson (2001) find that fluctuations in the common long-term trend in consumption, asset wealth, and labor income (hereby, consumption-wealth ratio) is a strong predictor of the excess returns. In this paper, we study the role of the consumption-wealth ratio in predicting the change in the nominal exchange rate of a large set of countries. We find evidence that fluctuations in the consumption wealth ratio help to predict in-sample all the currencies. In terms of out-of-sample forecasts, our results suggest that the consumption wealth ratio may play a significant role predicting the Canadian dollar at all horizons and at short-intermediate horizons for some currencies.
\end{abstract}

Keywords: Exchange Rates, Consumption-Wealth Ratio, Predictability

JEL Classification: C52, F31

\section{Introduction}

The difficulty in predicting exchange rates using macro fundamentals has been a challenge in international macroeconomics since the seminal paper by Meese and Rogoff (1983). They tested, across various exchange rates and forecast horizons, the predictive ability of a series of linear structural exchange rate models and found that none was able to outperform a simple random walk. Since then, the research in this area has tried to beat the naive random walk process without a conclusive result. Many authors have used expanded information sets or different functional forms, however, such efforts were unsuccessful or were shown to be fragile to minor changes in techniques and the data.

\footnotetext{
${ }^{*}$ We are specially grateful to Pierpaolo Benigno, Sydney Ludvigson and seminar participants at the Central Bank Reserve Bank of Peru and the Central Bank of Chile for helpful suggestions and comments. We also thank Lutz Kilian for making the data available and Michael McCracken for providing his test's codes. The views expressed herein are those of the authors and do not necessarily reflect those of the Central Bank of Chile or the Central Reserve Bank of Perú. Any errors are our own responsability.

${ }^{\dagger}$ E-mail: jselaive@bcentral.cl.

${ }^{\ddagger}$ Correspondence to Vicente Tuesta, Central Reserve Bank of Perú, Miroquesada \#441, Lima-Perú. E-mail: vtuesta@bcrp.gob.pe;
} 
Mark (1995) finds evidence in favor of the hypothesis of predictability at long forecast horizons, although his results are quite sensitive to the sample period. ${ }^{1}$ Kilian (1999) extends the sample period, and contrary to Mark's conjecture, finds little support for the monetary model and no evidence of increased long-horizon predictability. Faust, Rogers and Wright (2003) have recently shown that real-time of Federal Reserve forecasts of future independent money and output variables actually generate better forecasts of the future exchange rate than do actual future values of the independent variables. Kilian and Taylor (2003), using nonlinear monetary models, find strong evidence of predictability at horizons of two to three years, but not at shorter horizons.

Given the conflicting results using macroeconomics fundamentals, it is not obvious which direction the research has to turn. Some approaches suggest including rational speculative bubbles as determinants for the exchange rate (Meese, 1986 and Evans, 1986). ${ }^{2}$ Evans and Lyons (2002) suggest a microstructure approach to explain the short-run variations in the exchange rate horizons. ${ }^{3}$ Other authors like Clarida, Sarno, Taylor and Valente (2003) use models based on the term structure to forecast exchange rates. Omitted variables is another possible explanation for the lack of explanatory power in asset market models, and empirical researchers have shown considerable imagination in their specification searches, so it is not easy to think of variables that have escaped consideration in an exchange rate equation (Meese, 1990). ${ }^{4}$

There is still an on-going debate about exchange rate predictability. In general, and for a broad set of currencies, the monetary models and the pool of macro variables fit poorly out-of-sample. In trying to understand the difficulties in empirically modeling exchange rates, it is interesting to seek a unifying explanation for all major asset prices, including stocks and bonds as well as currencies.

Our paper will move in a new direction. We will use an estimated observable macro-finance variable constructed by Lettau and Ludvigson (2001, hereafter LL) to test its empirical implications on the real exchange rate predictability. Technically, they construct measures of nonobservable wealth as a function of observable variables. It is perhaps unrealistic to believe that only fundamentals that are observable by the econometrician should affect exchange rates, since observables are not explaining most of the exchange rate changes. As Engel and West (2003) point it out, it is certainly possible that a major role is played by unobservable determinants of the exchange rate that themselves nearly follow a random walk process.

In their paper Lettau and Ludvigson (2001) attribute a key role of fluctuations in the aggregate consumption-wealth ratio for predicting stock returns over short and intermediate horizons. ${ }^{5}$ When excess return are expected to be higher in the future, forward looking investors will react by increasing consumption out of current asset wealth and labor income. More recently, Guo (2003) shows that the forecasting

\footnotetext{
${ }^{1}$ This finding is often interpreted as evidence of increasing power at higher forecast horizons, however, this result has been questionable in the literature. Nelson and Kim (1993) Bollerslev and Hodrick (1995), Berkowitz and Giorgianni (1997) and Kirby (1997) have documented that conventional long-horizons tests are biased in favour of finding predictability.

${ }^{2}$ Flood and Hodrick (1990) conclude that the bubble alternative remains unconvincing.

${ }^{3}$ Evans and Lyons (2002) find that daily interdealer order flow explains 60 percent of daily exchange rate changes and consequently argue that flows are the proximate cause of exchange rate movements.

${ }^{4}$ Selaive and Tuesta (2003a, 2003b) present empirical evidence, based on an incomplete markets model, suggesting that the net foreign asset position of each country is a key variable in understanding both real and nominal exchange fluctuations. In this sense, an empirical evaluation of the predictability power of the NFA position over exchange rates is also appealing.

${ }^{5}$ Campbell and Mankiw (1989) show that the consumption-wealth ratio of a representative agent, derived from a budget constraint, is a function of future returns of market portfolio and the consumption growth.
} 
variables of the U.S excess stock return also forecast returns on international stock market indices, both in sample and out-of-sample. ${ }^{6}$ If americans invest in foreign currencies (or in assets denominated in foreign currencies), the returns of the portfolios will be finally a function, among other factors, of the relative depreciations or appreciations of the foreign currencies. This suggests a role for the consumption-wealth ratio to predict the nominal exchange rate. In a perfectly integrated market, forward looking investors in the rest of the world will find attractive to invest in a country where fluctuations in the consumption-wealth ratio are positive as long as these fluctuations remain for some periods.

In this paper we evaluate whether a model that includes fluctuations in the consumption-wealth ratio is able to beat in-sample and out-of-sample predictions of the random walk. First, we replicate Kilian (1999)'s results for the same set of countries and sample period. Then, we extend the sample of countries by including U.K, Italy and France, and evaluate the predictive power of the LL's consumption- wealth ratio variable.

Our main finding is that fluctuations in the consumption- wealth ratio has important predictive content for exchange rates. The overall in-sample forecasts are very good and our results suggest that fluctuations in the consumption-wealth ratio may play a significant role forecasting out-of-sample some currencies at short horizons ${ }^{7}$.

The rest of the paper is organized as follows. In section 2 we present a framework that rationalize the use of fluctuations in the consumption-wealth ratio as a predictor of the nominal exchange rate. In section 3 we present the econometric specification. Section 4 shows the empirical results, and section 5 concludes.

\section{Consumption-Wealth Ratio Fluctuations and Nominal Ex- change Rate}

The purpose of this section is to present a general framework that links fluctuations in the consumptionwealth ratio with changes in bilateral nominal exchange rates. This link is implicit in LL's derivation, so we just outline some extensions to their main results. From linearizing a budget constraint, they (LL) can express the consumption-wealth ratio as

$$
c_{t}-w_{t}=E_{t} \sum_{i=1}^{\infty} \rho_{w}^{i}\left(r_{w, t+i}-\Delta c_{t+i}\right),
$$

where $c_{t}, w_{t}, \rho_{w}$ and $r_{w}$ stand for the log deviations of consumption, aggregate wealth (human capital plus asset holdings), steady-state ratio of new investment to total wealth and net return on aggregate wealth, respectively. Equation (1) shows that if the consumption-wealth ratio is not constant, it must forecast changing returns to the market portfolio (or changing consumption growth).

LL approximate log aggregate wealth $\left(w_{t}\right)$ by the assets holding $\left(a_{t}\right)$ and the human capital $\left(h_{t}\right)$ as $w_{t}=\omega a_{t}+(1-\omega) h_{t}$, where $\omega$ equals the share of asset holdings in total wealth. Similarly, they assume

\footnotetext{
${ }^{6}$ Like many other assets, the exchange rate should depend on expectations of future variables, and in this sense Obstfeld and Rogoff (1998) suggest to treat the exchange rate as an asset price

${ }^{7}$ Inoue and Kilian (2003) conclude that results of in-sample test of predictability will typically be more credible than results of out-of-sample tests.
} 
that the nonstationary component of human capital can be well-described by aggregate labor income $y_{t}$, implying that $h_{t}=k+y_{t}+g_{t}$, where $k$ is a constant and $g_{t}$ is a mean zero stationary variable. Therefore, equation (1) takes the form

$$
c_{t}-\omega a_{t}-(1-\omega) y_{t}=E_{t} \sum_{i=1}^{\infty} \rho_{\omega}^{i}\left\{\left[\omega r_{a, t+i}+(1-\omega) r_{h, t+1}\right]-\Delta c_{t+1}\right\}+(1-\omega) g_{t}
$$

here, $r_{a, t}$ and $r_{h, t}$ correspond to the return on assets and human wealth, respectively. Under the presumption that all terms on the right hand side are stationary, then $c, a$ and $y$ must be cointegrated, and the left-hand side is the deviation in the common trend of $c_{t}, a_{t}$ and $y_{t}$. Following LL (2001), we denote this deviation as $c a y_{t}, i e, c_{t}-\omega a_{t}-(1-\omega) y_{t}=c a y_{t}$, which gives the trend deviation term or fluctuations in the aggregate consumption-wealth ratio. Equation (2) shows that cayt may be a good proxy for market expectations of future asset returns $r_{a, t+i}$.

Observe that $r_{a, t+i}$ embeds the return of different types of assets which may include domestic and/or foreign stocks (or funds), domestic and/or foreign bonds, and also foreign currencies. ${ }^{8}$ In this sense, $r_{a, t}$ can be expressed as the weighted sum of the returns of different assets in the portfolio as

$$
r_{a, t}=\sum_{j=1}^{N} \alpha_{j} r_{a j, t}
$$

where $\alpha_{j}$ is the weight of a particular asset within the investor's portfolio, ie, $\sum_{j=1}^{N} \alpha_{j}=1 .^{9}$

Then, we can argue that cayt may forecast variations in bilateral nominal exchange rates so far as they are part of the asset returns. Intuitively, when the bilateral nominal exchange rate (domestic currency/foreign currency) is expected to depreciate (increase), forward-looking domestic investors will react by increasing consumption out of current wealth, and therefore all else equal, positive fluctuations in the consumption-wealth ratio must be observed ${ }^{10}$. This holds as long as domestic investors hold foreign assets denominated in foreign currencies in their portfolios.

Table 1 present information about the portfolio holdings of equity securities of some countries based on information published by the International Monetary Fund (IMF) for year 1997. Remarkably, the shares of equity securities vary substantially across countries. While United Kingdom (UK) held $18 \%$ of total american investment of equity securities abroad, Italy (IT) held around 3.5\%. For Canada, the investment did not represent more that $6 \%$ of the total american investment, although it was more than $80 \%$ of the total holdings of equity securities in this country (not shown).

\footnotetext{
${ }^{8}$ Foreign currencies may not be explicit part of the portfolio of a domestic investor, but are implicit in the return -in domestic currency- of a foreign bond (or stock) denominated in foreing currency.

${ }^{9} \mathrm{In}$ an open economy framework when martets are perfectly integrated, an arbitrage condition will imply that the return of assets on domestic currency must equaliaze the return on assets denominated in foreign currency adjusted by the expected devaluation. Thus we can re-write the term $r_{a, t+1}$ using the following equilibrium condition $r_{a, t+1}=r_{a, t+1}^{*}+E_{t}\left(\Delta e_{t+1}\right)$. This conditon allows us to directly relate cayt with expected changes in the nominal exchange rate $E_{t}\left(\Delta e_{t+1}\right)$.

${ }^{10} \mathrm{It}$ is also possible to rationalize in context of open economy, the fact that fluctuations of the consumption-wealth ratio help predicting exchange rate. In a general equilibrium set up domestic and foreing budget constraints must be combined allong with arbitrage condition across countries.
} 
Table 1

Portfolio Holdings of Equity Securities: Year 1997

(Percentage and place of Total Investment in Each Country from USA )

\begin{tabular}{lllllll}
\hline \hline Country & $C A$ & $F R$ & $G R$ & $I T$ & $J P$ & $U K$ \\
USA & $6.0 / 5$ th & $7.1 / 4$ th & $5.4 / 6$ th & $3.5 / 8$ th & $11.3 / 2$ nd & $18.0 / 1$ st \\
& & & & & & \\
\hline \hline
\end{tabular}

Notes: - Authors' calculations based on Bilateral holdings of equity portfolios informed by the countries to the Coordinated Portfolio Investment Survey undertaken by the IMF.

Can we really predict nominal exchange rates? The consumption-wealth ratio will allow us to capture the positive (negative) income effect that Americans will enjoy when the return -measured in dollars- of foreign assets increases by the appreciation (depreciation) of the currency in which their foreign assets are denominated. ${ }^{11}$ From this portfolio effect, the cross-correlations between cayt and expected nominal exchange rate depreciation will be positive. ${ }^{12}$ In the pure smooth consumption effect, cayt tends to decline during expansions and rise prior to the onset of a recession. Thus, an expansion which is associated with an improvement of the fundamentals will trigger a nominal appreciation of the dollar (the currency becomes stronger) which are preceded by a decrease in cayt. Therefore, the cross-correlation between cayt and expected nominal exchange rate depreciation should also be positive. Finally, we have to consider a third effect related with the expectations of foreign households. If the foreign consumption-wealth ratio increases, and it does by a larger amount than cayt, foreign households will expect a higher return -measured in foreign currency- in the future, which will trigger an expected appreciation of the dollar, and we would observe a negative cross-correlation between cayt and expected nominal exchange rate depreciation. In a nutshell, there are three effects that could play a role in the comovements between cay $_{t}$ and exchange rates. However, either way, cay $t$ will reflect market expectations and it might help to predict exchange rates as long as currencies represent composites of investors' portfolios.

\section{Econometric Specification}

Many studies have found that the random walk provides more accurate forecasts than other models of exchange rate. In this sense, the random walk model is a good benchmark in order to judge the performance of the consumption-wealth ratio.

Structural or monetary models suggest that regressions of the form

$$
e_{t+k}-e_{t}=a_{k}+b_{k} z_{t}+\varepsilon_{t+k} \quad k=1,4,8,12,16
$$

will improve forecast accuracy relative to the random walk forecast

\footnotetext{
${ }^{11}$ The exchange rate is always expressed as american dollar/foreign currency.

${ }^{12} \mathrm{We}$ assume that americans and foreign investor hold bilateral positions, ie, americans hold foreing assets and foreign investors hold american assets. Both of them denominated in the corresponding domestic currency.
} 


$$
e_{t+k}-e_{t}=d_{k}+\varepsilon_{t+k} \quad k=1,4,8,12,16
$$

where, $e_{t}$ corresponds to the nominal exchange rate, and $z_{t}$ corresponds to macroeconomic fundamentals ${ }^{13}$.

The goal of our paper is to conduct an empirical examination of equation (4) to determine the predictive content of a new macro-financial fundamental. Therefore, we proceed evaluating the isolated role played by the consumption-wealth ratio at different horizons, and whether or not this variable improves forecast accuracy relative to the random walk forecast. To do so, we use as our unique fundamental $z_{t}$, the fluctuations consumption-wealth ratio, cayt. ${ }^{14}$ In this context, we will compare the predictions of the random walk model, equation (5), with those obtained using equation (6) below

$$
e_{t+k}-e_{t}=a_{k}+b_{k} c a y_{t}+\varepsilon_{t+k} \quad k=1,4,8,12,16
$$

Mean reversion in the nominal exchange rate may be detected by a $t-$ test of $H_{0}: b_{k}=0$ verus $H_{1}$ : $b_{k}<0$ for a given forecast horizon $k$, or jointly for all forecasts as $H_{0}: b_{k}=0$ for all $k$ versus $H_{1}: b_{k}<0$ for some $k$. On the other hand, the out-of-sample prediction may be evaluated using the DM test of Diebold and Mariano (1995). The test is based on a sequence of recursive forecasts and involve comparing the null of equal forecast accuracy against the one-sided alternative that forecast from the regression are more accurate than random walk forecasts.

Although by construction cayt $_{t}$ must have an expected value of zero since it is derived as the residual of a cointegrating relationship, it exhibits some persistence when we consider the period 1973.1-2001.4. ${ }^{15}$ Thus, we follow Kilian (1999)'s approach to deal with the persistence of the data and the small sample period available ${ }^{16}$. Similarly, asymptotic critical values for the DM statistic are severely biased in small samples. In order to overcome these size distortions critical values may be calculated based on the bootstrap approximation of the finite sample distribution of the test statistic under the null hypothesis of no exchange rate predictability ${ }^{17}$. Unlike asymptotic critical values, bootstrap critical values approximate the finite sample distribution of these tests. The p-values associated with the test statistics are estimated using a bootstrap algorithm similar to the one discussed by Mark (1995), and corrected by Kilian (1999) ${ }^{18}$. See Appendix 1 for the algorithm implemented.

\footnotetext{
${ }^{13}$ Standard versions of monetary models relate the exchange to economic fundamentals and the expected future exchange rate. In these models $z_{t} \equiv e_{t}-f_{t}$. and $f_{t}=m_{t}-m_{t}^{*}-\gamma\left(y_{t}-y_{t}^{*}\right)$. Where $m_{t}$ and $m_{t}^{*}$ corresponds to the money aggregates in both the domestic and foreign economies, and $y_{t}$ and $y_{t}^{*}$ are the log of domestic and foreign outputs, respectively.

${ }^{14}$ Recently, Wright (2003) applies a Bayesian Model Averaging approach that averages the forecasts of different models. His results suggest that the forecast generated using this approach are very close to those from the random walk forecast.

${ }^{15} \mathrm{LL}$ construct the variable cay $_{t}$ by estimating a cointegrating vector of asset wealth, consumption and income for the period 1952.I to 1998.III.

${ }^{16}$ It is well known that asymptotic critical values for the $t-t e s t$ statistics are biased in small samples.

${ }^{17}$ Mark and Sul (2001) applied the same approximation for a small panel of countries.

${ }^{18}$ Mark's inconsistency in permitting a drift in the bootstrap DGP but not in the benchmark forecast biased the bootstrap critical values. Kilian (1999) emphasized the importance of the treatment of the drift term in the forecasting procedures.
} 


\section{Empirical Results}

\subsection{Data and Summary Statistics}

For the benchmark monetary model we use the data set of Kilian (1999). It was constructed using OECD quarterly Main Economic Indicators for the period from 1973:01 1997:04. It includes the US dollar exchange rate for the Canadian dollar, German mark, Japanese yen, and the Swiss franc. We also include GNP and money supply (M1) for each country. We deseasonalize the data following Mark (1995) and Kilian (1999) by using a rolling aggregation of the data over the past year. We expand the sample of currencies by adding the French franc, Italian Lira and U.K pound. The variable cayt is taken from Lettau and Ludvigson (2001). ${ }^{19}$

Just to gain some intuition of the mechanism through which fluctuations in the consumption-wealth ratio could affect exchange rates, in figure 1 we plot the standarized trend deviation cayt and the standarized one-quarter, eight-quarter and twelve-quarter a head changes in the log of the nominal exchange rate for Canada over the period spanning the first quarter of 1973 until the fourth quarter of 2001. There are some episodes in which positive trend deviations of the consumption-wealth ratio anticipate nominal appreciations of the canadian dollar. Large fluctuations in the consumption-wealth ratio between 19881991 preceded a large nominal appreciation of the Canadian dollar from 1993-1996. These episodes could be associated with the effect of expectations of foreign investors mentioned previously. On the other hand, there are some episodes in which we observe positive deviations in cayt associated with nominal depreciations in the future (an increase in the nominal exchange rate) For example during periods 1983-85 and 1991-1994 we observe nominal a head depreciations vis a vis positive fluctuations in cay $_{t}$. These episodes could be linked with both the portfolio and pure smooth consumption effects described in section 2 .

Table 2 presents summary statistics for the nominal exchange rates and variable cayt $_{t}$. The crosscorrelation between this variable and the current nominal exchange rate are positive for most of the countries in the sample. The same holds for the first difference and the one period ahead variation in the exchange rate which may indicate that the portfolio and pure smooth consumption effects are the main driving forces for the pool of countries at these shorter horizons. This remarkably regularity breaks down when we look at the other cross-correlations ahead. There are minor changes in the cross-correlations when we split the sample period, although in some cases it turns out to be negative instead of positive.

\footnotetext{
${ }^{19}$ The description of the method of construction of cayt can be found in their paper.
} 
Table 2

Summary Statistics

Cross-Correlations: 1973.1 - 2001.4; [1973.1 - 1997.4]

\begin{tabular}{l|l|l|l|l|l|l}
\hline \multicolumn{9}{c}{ cayt vs } \\
\hline$e_{t}^{C a n}$ & $\Delta e_{t}^{C a n}$ & $\Delta e_{t+1}^{C a n}$ & $e_{t+4}^{C a n}-e_{t}^{C a n}$ & $e_{t+8}^{C a n}-e_{t}^{C a n}$ & $e_{t+12}^{C a n}-e_{t}^{C a n}$ & $e_{t+16}^{C a n}-e_{t}^{C a n}$ \\
$0.15[-0.38]$ & $0.04[-0.04]$ & $0.00[-0.10]$ & $-0.08[-0.14]$ & $-0.15[-0.16]$ & $-0.19[-0.20]$ & $-0.11[-0.11]$ \\
$e_{t}^{F r n}$ & $\Delta e_{t}^{F r n}$ & $\Delta e_{t+1}^{F r n}$ & $e_{t+4}^{F r n}-e_{t}^{F r n}$ & $e_{t+8}^{F r n}-e_{t}^{F r n}$ & $e_{t+12}^{F r n}-e_{t}^{F r n}$ & $e_{t+16}^{F r n}-e_{t}^{F r n}$ \\
$0.09[-0.15]$ & $0.14[0.13]$ & $0.11[0.10]$ & $0.23[0.18]$ & $0.24[0.16]$ & $0.20[0.16]$ & $0.07[0.08]$ \\
$e_{t}^{G r m}$ & $\Delta e_{t}^{G r m}$ & $\Delta e_{t+1}^{G r m}$ & $e_{t+4}^{G r m}-e_{t}^{G r m}$ & $e_{t+8}^{G r m}-e_{t}^{G r m}$ & $e_{t+12}^{G r m}-e_{t}^{G r m}$ & $e_{t+16}^{G r m}-e_{t}^{G r m}$ \\
$0.23[0.47]$ & $0.06[0.0]$ & $0.07[-0.01]$ & $0.12[0.00]$ & $0.16[0.05]$ & $0.06[0.01]$ & $-0.09[-0.09]$ \\
$e_{t}^{I t y}$ & $\Delta e_{t}^{I t y}$ & $\Delta e_{t+1}^{I t y}$ & $e_{t+4}^{I t y}-e_{t}^{I t y}$ & $e_{t+8}^{I t y}-e_{t}^{I t y}$ & $e_{t+12}^{I t y}-e_{t}^{I t y}$ & $e_{t+16}^{I t y}-e_{t}^{I t y}$ \\
$0.00[-0.50]$ & $0.09[0.11]$ & $-0.10[-0.59]$ & $-0.09[-0.56]$ & $-0.21[-0.51]$ & $-0.31[-0.45]$ & $-0.49[-0.49]$ \\
$e_{t}^{J p n}$ & $\Delta e_{t}^{J p n}$ & $\Delta e_{t+1}^{J p n}$ & $e_{t+4}^{J p n}-e_{t}^{J p n}$ & $e_{t+8}^{J p n}-e_{t}^{J p n}$ & $e_{t+12}^{J p n}-e_{t}^{J p n}$ & $e_{t+16}^{J p n}-e_{t}^{J p n}$ \\
$0.07[0.50]$ & $0.10[0.08]$ & $0.10[0.10]$ & $0.11[0.08]$ & $0.05[0.06]$ & $0.07[0.06]$ & $0.00[0.00]$ \\
$e_{t}^{S w t}$ & $\Delta e_{t}^{S w t}$ & $\Delta e_{t+1}^{S w t}$ & $e_{t+4}^{S w t}-e_{t}^{S w t}$ & $e_{t+8}^{S w t}-e_{t}^{S w t}$ & $e_{t+12}^{S w t}-e_{t}^{S w t}$ & $e_{t+16}^{S w t}-e_{t}^{S w t}$ \\
$0.29[0.57]$ & $0.10[0.0]$ & $0.04[-0.03]$ & $0.06[-0.07]$ & $0.06[-0.08]$ & $-0.03[-0.10]$ & $-0.20[-0.20]$ \\
$e_{t}^{U K}$ & $\Delta e_{t}^{U K}$ & $\Delta e_{t+1}^{U K}$ & $e_{t+4}^{U K}-e_{t}^{U K}$ & $e_{t+8}^{U K}-e_{t}^{U K}$ & $e_{t+12}^{U K}-e_{t}^{U K}$ & $e_{t+16}^{U K}-e_{t}^{U K}$ \\
$-0.18[-0.50]$ & $0.10[0.07]$ & $0.13[0.13]$ & $0.19[0.17]$ & $0.30[0.29]$ & $0.43[0.43]$ & $0.36[0.36]$ \\
\hline
\end{tabular}

Notes: Authors' calculations based on LL (2001) and data is taken from the IMF

Univariate Statistics

1973.1 - 2001.4

\begin{tabular}{lllllllll}
\hline \hline & $e_{t}^{\text {Can }}$ & $e_{t}^{\text {Frn }}$ & $e_{t}^{\text {Grm }}$ & $e_{t}^{\text {Ity }}$ & $e_{t}^{\text {Jpn }}$ & $e_{t}^{\text {Swt }}$ & $e_{t}^{U K}$ & cayt \\
Mean & -0.09 & 0.06 & -0.3 & 0.18 & -2.22 & -0.25 & 0.24 & 0.70 \\
Standard Deviation & 0.05 & 0.09 & 0.09 & 0.15 & 0.16 & 0.11 & 0.07 & 0.01 \\
Autocorrelation & 0.96 & 0.94 & 0.95 & 0.96 & 0.98 & 0.95 & 0.93 & 0.83 \\
& & & & & & & & \\
\hline \hline
\end{tabular}

Notes: Authors' calculations based on LL (2001) and the data is taken from the IMF

In the univariate moments of the data, we observe a higher persistence of the nominal exchange rate with respect to cay, and large differences in terms of volatilities in the exchange rates across countries.

\subsection{Replicating Mark (1995)'s results}

To facilitate the comparison of our work and existing literature, we replicate Mark (1995)'s seminal paper. Mark provided evidence that current-period deviations from the equilibrium exchange rate help predict future changes in nominal exchange rates. The goal of his paper is to conduct an empirical examination of equation (4) to determine the predictive content of the state variable $z_{t}$. He does not estimate a wellarticulated model of exchange rate dynamics. Kilian (1999) show that the bootstrap procedure used by Mark is not entirely correct, and may result in spurious inference. In this context, we follow Kilian's procedure to analyze the role played by fundamental and establish their predictive content. 
We consider a model in which the current value of foreign exchange rate can be expressed in terms of economic fundamentals (equation (4)).

All test results are presented in the form of bootstrap p-values based on 2000 bootstrap replications. $t_{20}, t_{A}$ are the t-statistics for the slope coefficient in regression (4) where the subscript indicates whether the standard errors are calculated using a fixed truncation lag of 20 or Andrews' (1991) procedure. ${ }^{20}$ $D M_{20}$ and $D M_{A}$ refer to the corresponding Diebold-Mariano statistic. Like Kilian (1999), we also present the joint test across the five time horizons for all statistics.

There are two criteria to analyze exchange rate predictability. The first one is whether the joint test is significant at 10 percent level (p-values smaller than 0.1 ). The second criterion is evidence of declining $\mathrm{p}$-values as the forecast horizon is increased. Any p-value below 0.1 implies a rejection of the random walk null hypothesis at the $10 \%$ of significance level.

In Table 3, we display Kilian's results for the four typical economies, Canada, Germany, Japan and Switzerland. The period correspond to 1973.1-1997.4. ${ }^{21}$ There is important evidence of overall predictability in the out-of-sample statistics for Canada and Switzerland ( $\mathrm{p}$-values associated to the joint tests are below 0.1). Although, there is no evidence of increase predictability at longer horizons which is puzzling given the widespread presumption that the power of long-horizon regressions test improves at longer horizons. For Canada and Switzerland the p-values associated to the out-of-sample statistics are increasing instead of decreasing. There is no evidence of overall predictability neither for Japan nor for Germany. With respect to the in-sample statistics, Kilian's result show that there is evidence of exchange rate predictability only for Switzerland.

\subsection{The Consumption-wealth ratio as a new fundamental}

In Table 4 we present bootstrap p-values for the test of the random walk null, using as a predictable variable fluctuations in the consumption-wealth ratio, cayt. In Table 5 , we expand the set of countries by including the French Franc, the italian Lira and U.K pound. First, as we mentioned before these p-values should fall at longer horizons

The overall in-sample forecasts are very good. For most of the countries we observe p-values below 10\%. This result contrast with Kilian's findings for Germany and Japan. There is some evidence of decreasing p-values for Canada, Japan and France across all horizons and for Germany, Switzerland, Italy and UK at intermediate horizons. There is little difference between the $t_{20}$ and $t_{A}$. In addition, besides the pattern of predictability, in most of the cases we find that the regression using the consumption-wealth ratio is significantly more accurate than the random walk. For example, for $k=16$ we are able to reject the random walk for six of the seven countries using both $t_{20}$ and $t_{A}$. Furthermore, in five cases the joint test statistic is significant at the $10 \%$ level. This evidence allows us to reject conclusively the random walk

\footnotetext{
${ }^{20}$ Extending the forecast horizon beyond the sampling interval induces serial correlation in the error. The two methods employed here differ according to the rule used to determine the truncation lag for the Bartlett window. The first method arbitrary sets the truncation lag at 20 . The second method employs a data-dependent formula provided by Donald Andrews (1991).

${ }^{21}$ This results correspond to Figure 5, pp 504 in Kilian's (1999) paper
} 
model. Therefore, our results suggest that the consumption-wealth ratio helps improve in-sample forecast accuracy relative to the random walk for a large set of countries.

The results of predictability out-of-sample are less conclusive. Columns 4 and 5 show the corresponding p-values for , $D M_{20}$ and $D M_{A}$ test of out-of-sample accuracy. The main result is that there is strong evidence of predictability at longer horizons for Canada given that the p-values associated to the out-of sample statistics are decreasing. This contrast remarkably with Kilian's finding of increasing p-values. For the rest of the countries there is no conclusive evidence that our model beats the random walk. There is some evidence that a regression using fluctuations in the consumption-wealth ratio is significantly more accurate than the random walk at shorter-horizons, for instance, for $k=4$ we are able to reject the random walk model for the swiss franc at $13 \%$ level $\left(D M_{20}\right.$ and $D M_{A}$ ), and for $k=1$ we are able to reject the random walk for the italian Lira and U.K pound. As a bottom line, our results suggest that fluctuations in the consumption-wealth ratio may play a significant role forecasting some currencies at short horizons.

In Table 6 we extend the sample period until 2002.3 for Canada, Japan, Switzerland and United Kingdom. Our results out-of-sample forecasts improve significantly for Switzerland and United Kingdom. The p-values associated to $D M_{20}, D M_{A}$ and joint tests for Switzerland gets lower than 0.2 (it was in the order of 0.4 using the previous sample) and the corresponding for U.K start to get decreasing from the eight quarter on.

Given the less evidence in terms of the of out-of sample predictive value of cayt, we check for robustness by performing the $E N C-N E W$ tests developed by Clark and McCracken (2001) ${ }^{22}$. As shown in Table 7 the $E N C-N E W$ test confirms our previous findings. There is little evidence of out-of sample predictability for the period 1973-1997. Similar results are reported once we extend the sample (not shown). However, it is worthwhile to mention that there is strong evidence of out-of sample predictability for France using the $E N C-N E W$ contrasting the results obtained with $D M_{20}$, and $D M_{A}$.

The above unconvincing patters in predictive ability out of sample could be the result of structural changes in some economies. Therefore, and more on the technical grounds, it may also be interesting to evaluate the behavior of of out-of-sample tests in the presence of structural change (see Clark and McCracken 2002) ${ }^{23}$. In addition, our results might also be influenced by the DGP utilized in order to overcome size distorsions (see appendix), in this sense, trying with a different DGP could be useful.

It is well known that significant in-sample evidence of predictability does not guarantee significant outof-sample predictability ${ }^{24}$. This should not be interpreted that in-sample evidence is likely to be spurious. Inoue and Kilian (2003) have shown that this interpretation is not correct and, moreover, they show that there is no presumption that in-sample tests are less reliable than out-of-sample tests. In fact Inoue and

\footnotetext{
${ }^{22}$ In particular they show that the commonly used t-type test of forecast accuracy has lower power than the ENC-NEW tests. For instance, McCracken and Sapp (2002) report strong evidence of exchange rate predictability using the ENC-NEW test.

${ }^{23}$ Clark and McCracken (2002) conclude, based on an empirical application relating GDP growth with the interest rate term spread, that structural breaks can explain why is common to find evidence of predictive content in-sample but not out-of-sample.

${ }^{24}$ As Clark and McCracken (2003) pointed out some of the differences between in-sample and out-of-sample results on predictive ability may be due to model inestability. Moreover, in an application, they show robust evidence that structural shifts can account for the out-of sample breakdown in predictive power found in many empirical works.
} 
Kilian (2003) conclude that in-sample tests are more credible.

\section{Conclusions}

The difficulty in predicting exchange rates has been a long-standing problem in international macroeconomics. After the seminal paper by Meese and Rogoff (1983) many researchers have tried to find variables and/or models able to beat the random walk process. The negative results have produced a conventional wisdom that exchange rate changes cannot be forecast or cannot be forecast using economic fundamentals.

On the other hand, predicting stock returns has also been a permanent challenge in financial research. Recently, Lettau and Ludvigson (2001) present evidence suggesting the importance of linking macroeconomic and financial markets by noting that consumption, asset holdings, and labor income share a common long-term trend. Their results show that transitory deviations from this common trend, the consumption-wealth ratio, are strong predictors of assets returns. In this paper, we have explored whether the consumption-wealth ratio can help in forecasting exchange rates at both short and long horizons. Our results suggest that the consumption wealth ratio does an excellent job in terms of in-sample forecasts, and may play a significant role, although to a lesser extent, in forecasting out-of-sample some currencies at short horizons. We present evidence that the use of the fluctuations in the consumption-wealth ratio improves forecast accuracy at shorter horizons for Canada and United Kingdom.

In this work we have examined the forecasting ability of the consumption-wealth ratio through a linear statistical model, but there has been recent work documenting various nonlinearities in the spot exchange rate from fundamentals which suggests a promising research to pursue (see Kilian and Taylor, 2003). On the other hand, other international-macro variables may continue to shed light on the mechanism that drives variations in exchange rates, and in particular, the bilateral net foreign asset position among countries may be a good variable to consider (see Selaive and Tuesta, 2003a, 2003b). Finally, other future research might explore the way that expectations of assets prices are formed and how the factors such as risk aversion and transaction costs generate high nominal exchange rate variability 


\section{APPENDIX}

\section{Bootstrap Algorithm}

We follow closely Mark's (1995) algorithm. Unlike Mark (1995), we allow for a drift in both the benchmark forecast and the DGP. Under the null hypothesis of exchange rate predictability we postulate the following bootstrap DGP

$$
\begin{aligned}
e_{t}-e_{t-1} & =a_{0}+\varepsilon_{1, t} \\
\text { cay }_{t} & =b_{0}+\sum_{j=1}^{p} b_{j} c a y_{t-j}+\varepsilon_{2, t}
\end{aligned}
$$

1. We estimate each equation of model (7) by OLS and generate bootstrap data conditional on the fitted values. The lag order $p$ has been determined under the null by the AIC criterion. Then we construct the test statistic of interest, $\widehat{\lambda}$.

2. Take the resulting residuals and sample them with replacement to obtain a set of bootstrap residuals $\left(\varepsilon_{1, t}^{*}, \varepsilon_{2, t}^{*}\right)$.

3. Based on the fitted model generate sequences of observations $\left\{\triangle e_{t}^{*}\right\},\left\{\operatorname{cay}_{t}^{*}\right\}$ of the same length of the original data where $e_{t}^{*}$ is based on cumulative sums of the realizations of the bootstrap datagenerating process:

$$
\begin{aligned}
\triangle e_{t}^{*} & =\widehat{a}_{0}+\varepsilon_{1, t}^{*} \\
\operatorname{cay}_{t}^{*} & =\widehat{b}_{0}+\sum_{j=1}^{p} \widehat{b}_{j}^{*} c a y_{t-j}^{*}+\varepsilon_{2, t}^{*}
\end{aligned}
$$

To initialize the process assume $c a y_{t-1}^{*}=0$, for $j=p-1, \ldots 1$. We repeat this step 2000 times.

4. Then estimate the equation (6) for each of the 2000 replications

$$
e_{t+k}^{*}-e_{t}^{*}=a_{k}^{*}+b_{k}^{*} c a y_{t}^{*}+\varepsilon_{t+k}^{*} \quad k=1,4,8,12,16
$$

and construct the test statistic of interest $\widehat{\lambda}^{*}$

5. Use the bootstrapped test statistic to obtain an empirical distribution to determine the p-value of the test statistic $\widehat{\lambda}$. 


\section{References}

[1] Berkowitz, Jeremy and Lorenzo Giorgianni (2001), " Long-horizon Exchange Rate Predictability?", Review of Economic and Statistics,

[2] Bilson, John (1978), "Rational Expectations and the Exchange Rate", in Jacob A. Frenkel and Harry G. Johnson, eds, The Economics of Exchange Rates: Selected Studies. Reading, MA: Addison-Wesley, pp. $75-76$.

[3] Bollerslev, Tim and Robert J. Hodrick (1995), "Financial Market Efficiency Tests", in M.H. Pesaran and M. R. Wickens (eds), Handbook of Applied Econometrics, Blackwell, Cambridge, MA.

[4] Campbell, John and Gregory Mankiw (1989), "Consumption, Income, and Interest Rates: Reinterpreting the Time Series Evidence", in Oliver Blanchard and Stanley Fischer, eds. NBER Macroeconomic Annual, Cambridge, MA. MIT Press.

[5] Clarida, Richard, Lucio Sarno, Mark Taylor and Giorgio Valente (2003), "The Out-of Sample Success of Term Structure Models as Exchange Rate Predictors: A Step Beyond", Journal of International Economics, forthcoming.

[6] Clark, Todd and Michael McCracken (2001), "Test of Equal Forecast Accuracy and Encompassing for Nested Models", Journal of Econometrics 105, 85-110

[7] Clark, Todd and Michael McCracken (2002), "Forecast-Based Model Selection in the Presence of Structural Breaks", Research Working Paper 02-05, Federal Reserve Bank of Kansas City

[8] Diebold, Francis and Roberto Mariano (1995), "Comparing Predictive Accuracy", Journal of Business and Economic Statistics 13, 253-262.

[9] Engel, Charles and Kenneth West (2003), "Exchange Rate and Fundamentals", Manuscript, University of Wisconsin

[10] Evans, Martin and Richard Lyons (2002), "Order Flow and Exchange Rate Dynamics" Journal of Political Economy, February 2002, 170-180.

[11] Faust, Jon, John Rogers and Jonathan Wright (2003), "Exchange Rate Forecasting: The Errors We've Really Made" Journal of International Economics 60, 35-59.

[12] Frankel, Jefrey (1979), On the Mark: A Theory of Exchange Rates Based on Real Interest Rate Differentials", American Economic Review 69, 610-622.

[13] Guo, Hui (2003), "On the Out-of Sample Stock Return Predictability: The International Evidence", Working Paper 2003-012, Federal Reserve Bank of St. Louis. 
[14] Inoue, Atsushi and Lutz Kilian (2003), "In-Sample or Out-of-Sample Tests of Predictability: Which One Should We Use?" mimeo.

[15] Kilian, Lutz (1999), "Exchange Rates and Monetary Fundamentals: What do We Learn from Longhorizon Regressions?, Journal of Applied Econometrics 14, 491-510.

[16] Kilian, Lutz and Mark P. Taylor (2003), "Why is it so difficult to beat the random walk forecast of exchange rates?", Journal of International Economics 60, 85-107.

[17] Kirby, Chris (1997), "Measuring the Predictable Variation in Stock and Bond Returns", Review of Financial Studies 10, 579-630.

[18] Lettau, Martin and Sydney Ludvigson (2001), "Consumption, Aggregate Wealth, and Expected Stock Returns", Journal of Finance 3, 815-849.

[19] Lettau, Martin and Sydney Ludvigson (2002), "Time-varying Risk Premia and the Cost of Capital: An Alternative Implication of the Q Theory of Investment", Journal of Monetary Economics 49, 31-66.

[20] Mark, Nelson (1995), "Exchange Rates and Fundamentals: Evidence on Long-horizon Predictability". American Economic Review 85, 201-218.

[21] Mark, Nelson and Donggyu Sul (2001), "Nominal Exchange Rates and Monetary Fundamentals Evidence from a Small Post-Bretton Woods Panel", Journal of International Economics 53, 29-52.

[22] McCracken, Michael and Stephen Sapp (2002), "Evaluating the Predictability of Exchange Rates using Long-Horizon Regressions", Manuscript, University of Western Ontario

[23] Meese, Richard (1990) "Currency Fluctuations on the post-Bretton Woods era", Journal of Economic Perspectives 4: 3-24.

[24] Meese, Richard and Kenneth Rogoff (1983), "Empirical Exchange Rate Models of the Seventies: Do They Fit Out of Sample?", Journal of International Economics 14, pp. 3-24.

[25] Mussa, Michael, "The Exchange Rate, the Balance of Payments and Monetary and Fiscal Policy Under a Regime of Controlled Floating" Scandinavian Journal of Economics 78, pp. 229-248

[26] Nelson, Charles and Myung Kim (1993), "Predictable Stock Returns: The Role of Small-sample Bias", Journal of Finance 48, pp. 641-661.

[27] Selaive, Jorge and Vicente Tuesta (2003a), "Net Foreign Assets and Imperfect Pass-through: The Consumption Real Exchange Rate Anomaly", Board of Governors of the Federal Reserve System, International Finance Discussion Paper \#764 
[28] Selaive, Jorge and Vicente Tuesta (2003b), "Net Foreign Assets and Imperfect Financial Integration: An Empirical Approach", Central Bank of Chile working paper \#252.

[29] Wright, Jonathan (2003), "Bayesian Model Averaging and Exchange Rate Forecasts", Board of Governors of the Federal Reserve System, International Finance Discussion Paper \#779. 


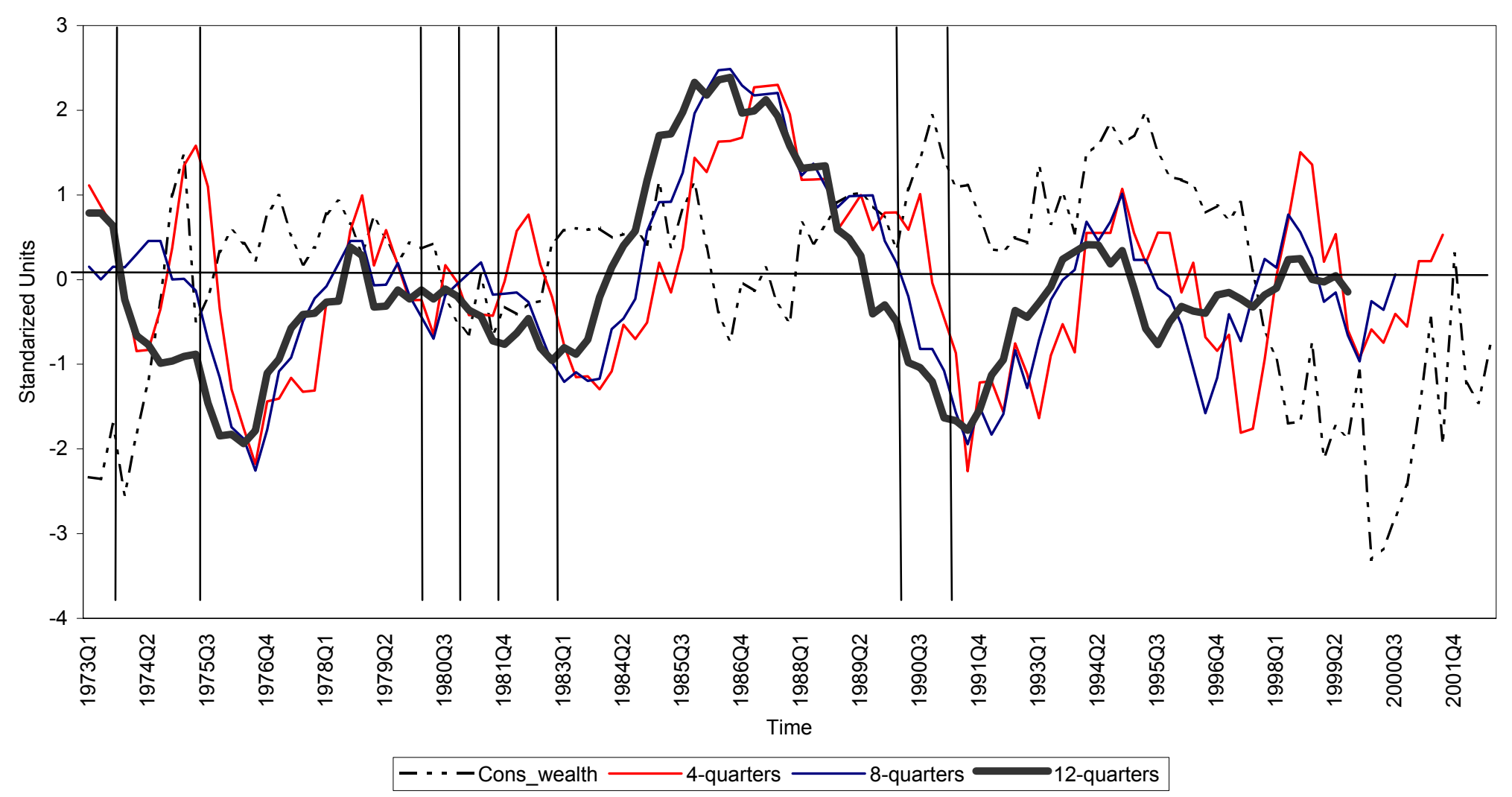

Figure 1:Ahead- change in the canadian dollar exchange rate and trend deviations. Both series are normalized to standard deviations of unity. The sample period is from 1973Q1 until 2002Q3 . Periods within bars denote NBER recessions. 
Table 3:

Bootstrap p-values under Ho: random walk with drift in the exchange rate. Replication of Kilian's result (1999).

Results are shown for alternative forecast horizons $\mathrm{k}=1,4,8,12,16$.

Joint refers to the p-value for the joint test statistic for all horizons. Sample period 1973 Q1 1997 Q4

\begin{tabular}{|c|c|c|c|c|c|}
\hline & quarter & $\mathbf{t}(20)$ & $t(A)$ & $\mathrm{DM}(20)$ & $\mathrm{DM}(\mathrm{A})$ \\
\hline \multirow[t]{6}{*}{$\overline{\text { Canada }}$} & 1 & 0.081 & 0.092 & 0.033 & 0.050 \\
\hline & 4 & 0.203 & 0.189 & 0.045 & 0.055 \\
\hline & 8 & 0.246 & 0.243 & 0.022 & 0.018 \\
\hline & 12 & 0.405 & 0.433 & 0.070 & 0.066 \\
\hline & 16 & 0.483 & 0.515 & 0.121 & 0.112 \\
\hline & joint & 0.272 & 0.405 & 0.060 & 0.061 \\
\hline \multirow[t]{6}{*}{ Germany } & 1 & 0.163 & 0.190 & 0.159 & 0.163 \\
\hline & 4 & 0.210 & 0.176 & 0.168 & 0.170 \\
\hline & 8 & 0.264 & 0.202 & 0.226 & 0.226 \\
\hline & 12 & 0.280 & 0.279 & 0.272 & 0.274 \\
\hline & 16 & 0.300 & 0.316 & 0.350 & 0.356 \\
\hline & joint & 0.369 & 0.372 & 0.312 & 0.317 \\
\hline \multirow[t]{6}{*}{ Japan } & 1 & 0.272 & 0.148 & 0.073 & 0.056 \\
\hline & 4 & 0.262 & 0.277 & 0.103 & 0.106 \\
\hline & 8 & 0.221 & 0.214 & 0.104 & 0.108 \\
\hline & 12 & 0.225 & 0.217 & 0.201 & 0.200 \\
\hline & 16 & 0.280 & 0.280 & 0.337 & 0.347 \\
\hline & joint & 0.298 & 0.289 & 0.165 & 0.161 \\
\hline \multirow[t]{6}{*}{ Switzerland } & 1 & $\mathbf{0 . 0 5 7}$ & 0.027 & 0.018 & 0.006 \\
\hline & 4 & 0.078 & 0.049 & 0.021 & 0.020 \\
\hline & 8 & 0.058 & 0.053 & 0.029 & 0.032 \\
\hline & 12 & 0.015 & 0.013 & 0.045 & 0.045 \\
\hline & 16 & 0.001 & 0.002 & 0.071 & 0.057 \\
\hline & joint & 0.001 & 0.002 & 0.081 & 0.076 \\
\hline
\end{tabular}


Table 4:

Bootstrap p-values under Ho: random walk with drift in the exchange rate. A model with contemporaneous fluctuations in the consumption-wealth ratio. Results are shown for alternative forecast horizons $\mathrm{k}=1,4,8,12,16$.

Joint refers to the p-value for the joint test statistic for all horizons. Sample period 1973 Q1 1997 Q4

\begin{tabular}{|c|c|c|c|c|c|}
\hline & quarter & $t(20)$ & $t(A)$ & $\mathrm{DM}(20)$ & $\mathrm{DM}(\mathrm{A})$ \\
\hline \multirow[t]{6}{*}{ Canada } & 1 & 0.125 & 0.139 & 0.275 & 0.334 \\
\hline & 4 & 0.061 & 0.071 & 0.150 & 0.150 \\
\hline & 8 & 0.067 & 0.059 & 0.174 & 0.168 \\
\hline & 12 & 0.054 & 0.055 & 0.134 & 0.110 \\
\hline & 16 & 0.050 & 0.050 & 0.113 & 0.054 \\
\hline & joint & 0.105 & 0.091 & 0.209 & 0.097 \\
\hline \multirow[t]{6}{*}{ Germany } & 1 & 0.041 & 0.052 & 0.441 & 0.366 \\
\hline & 4 & 0.033 & 0.035 & 0.385 & 0.372 \\
\hline & 8 & 0.029 & 0.010 & 0.370 & 0.371 \\
\hline & 12 & 0.039 & 0.033 & 0.443 & 0.459 \\
\hline & 16 & 0.034 & 0.040 & 0.590 & 0.640 \\
\hline & joint & 0.079 & 0.043 & 0.749 & 0.760 \\
\hline \multirow[t]{6}{*}{ Japan } & 1 & 0.134 & 0.136 & 0.475 & 0.629 \\
\hline & 4 & 0.117 & 0.136 & 0.698 & 0.695 \\
\hline & 8 & 0.084 & 0.067 & 0.825 & 0.857 \\
\hline & 12 & 0.089 & 0.072 & 0.949 & 0.972 \\
\hline & 16 & 0.093 & 0.074 & 0.955 & 1.000 \\
\hline & joint & 0.190 & 0.137 & 0.912 & 0.948 \\
\hline \multirow[t]{6}{*}{ Switzerland } & 1 & 0.007 & 0.013 & 0.134 & 0.140 \\
\hline & 4 & 0.008 & 0.007 & 0.125 & 0.129 \\
\hline & 8 & 0.012 & 0.009 & 0.255 & 0.258 \\
\hline & 12 & 0.021 & 0.018 & 0.473 & 0.499 \\
\hline & 16 & 0.018 & 0.016 & 0.825 & 0.866 \\
\hline & joint & 0.030 & 0.030 & 0.426 & 0.431 \\
\hline
\end{tabular}


Table 5:

Bootstrap p-values under Ho: random walk with drift in the exchange rate. A model with contemporaneous fluctuations in the consumption-wealth ratio. Results are shown for alternative forecast horizons $\mathrm{k}=1,4,8,12,16$.

Joint refers to the p-value for the joint test statistic for all horizons. Sample period 1973 Q1 1997 Q4

\begin{tabular}{|c|c|c|c|c|c|}
\hline & quarter & $\mathbf{t}(\mathbf{2 0})$ & $t(A)$ & DM(20) & $\mathrm{DM}(\mathrm{A})$ \\
\hline \multirow[t]{6}{*}{ France } & 1 & 0.124 & 0.178 & 0.359 & 0.390 \\
\hline & 4 & 0.051 & 0.039 & 0.532 & 0.686 \\
\hline & 8 & 0.006 & 0.004 & 0.561 & 0.616 \\
\hline & 12 & 0.009 & 0.002 & 0.569 & 0.602 \\
\hline & 16 & 0.021 & 0.005 & 0.592 & 0.600 \\
\hline & joint & 0.021 & 0.006 & 0.801 & 0.804 \\
\hline \multirow[t]{6}{*}{ Italy } & 1 & 0.028 & 0.052 & 0.069 & 0.056 \\
\hline & 4 & 0.036 & 0.022 & 0.231 & 0.232 \\
\hline & 8 & 0.024 & 0.023 & 0.411 & 0.436 \\
\hline & 12 & 0.039 & 0.041 & 0.449 & 0.474 \\
\hline & 16 & 0.059 & 0.057 & 0.742 & 0.815 \\
\hline & joint & 0.077 & 0.061 & 0.356 & 0.332 \\
\hline \multirow[t]{6}{*}{ United Kingdom } & 1 & 0.024 & 0.040 & 0.098 & 0.066 \\
\hline & 4 & 0.001 & 0.010 & 0.266 & 0.273 \\
\hline & 8 & 0.000 & 0.000 & 0.396 & 0.423 \\
\hline & 12 & 0.000 & 0.000 & 0.433 & 0.435 \\
\hline & 16 & 0.015 & 0.010 & 0.261 & 0.263 \\
\hline & joint & 0.000 & 0.000 & 0.442 & 0.378 \\
\hline
\end{tabular}


Table 6:

Bootstrap p-values under Ho: random walk with drift in the exchange rate. A model with contemporaneous fluctuations in the consumption-wealth ratio. Results are shown for alternative forecast horizons $\mathrm{k}=1,4,8,12,16$.

Joint refers to the p-value for the joint test statistic for all horizons. Sample period 1973 Q1 2002 Q3

\begin{tabular}{|c|c|c|c|c|c|}
\hline & quarter & $\mathbf{t}(20)$ & $t(A)$ & $\mathrm{DM}(20)$ & $\mathrm{DM}(\mathrm{A})$ \\
\hline \multirow[t]{6}{*}{ Canada } & 1 & 0.255 & 0.282 & 0.480 & 0.512 \\
\hline & 4 & 0.205 & 0.200 & 0.618 & 0.662 \\
\hline & 8 & 0.145 & 0.139 & 0.570 & 0.632 \\
\hline & 12 & 0.141 & 0.147 & 0.512 & 0.484 \\
\hline & 16 & 0.141 & 0.139 & 0.311 & 0.311 \\
\hline & joint & 0.221 & 0.195 & 0.533 & 0.544 \\
\hline \multirow[t]{6}{*}{ Japan } & 1 & 0.131 & 0.152 & 0.343 & 0.433 \\
\hline & 4 & 0.105 & 0.101 & 0.441 & 0.489 \\
\hline & 8 & 0.084 & 0.055 & 0.546 & 0.575 \\
\hline & 12 & 0.076 & 0.048 & 0.599 & 0.597 \\
\hline & 16 & 0.066 & 0.039 & 0.696 & 0.802 \\
\hline & joint & 0.106 & 0.053 & 0.712 & 0.757 \\
\hline \multirow[t]{6}{*}{ Switzerland } & 1 & 0.002 & 0.007 & 0.047 & 0.054 \\
\hline & 4 & 0.008 & 0.006 & 0.030 & 0.031 \\
\hline & 8 & 0.006 & 0.001 & 0.084 & 0.082 \\
\hline & 12 & 0.007 & 0.002 & 0.180 & 0.180 \\
\hline & 16 & 0.002 & 0.000 & 0.331 & 0.333 \\
\hline & joint & 0.002 & 0.001 & 0.168 & 0.167 \\
\hline \multirow[t]{6}{*}{ United Kingdom } & 1 & 0.024 & 0.045 & 0.086 & 0.075 \\
\hline & 4 & 0.003 & 0.007 & 0.231 & 0.235 \\
\hline & 8 & 0.001 & 0.000 & 0.283 & 0.284 \\
\hline & 12 & 0.002 & 0.000 & 0.285 & 0.282 \\
\hline & 16 & 0.020 & 0.018 & 0.172 & 0.179 \\
\hline & joint & 0.003 & 0.001 & 0.279 & 0.281 \\
\hline
\end{tabular}




\section{Table 7: ENC-NEW}

Bootstrap p-values under Ho: random walk with drift in the exchange rate. A model with contemporaneous fluctuations in the consumption-wealth ratio.

Results are shown for alternative forecast horizons $\mathrm{k}=1,4,8,12,16$. Values below the horizontal line are significant at the $10 \%$ level.

Joint refers to the p-value for the joint test statistic for all horizons. Sample period 1973 Q1 1997 Q4. ENC_NEW is the modified Harvey et al. (1999) statistic,

as proposed by Clark and McCracken (1999). Under the null, the restricted model encompass the unrestricted one.

\begin{tabular}{|c|c|c|c|c|c|c|c|}
\hline quarter & Canada & Germany & Japan & Switzerland & France & Italy & United Kingdom \\
\hline 1 & 0.932 & 0.947 & 0.865 & 0.877 & 0.072 & 0.491 & 0.813 \\
\hline 4 & 0.785 & 0.865 & 0.917 & 0.933 & 0.147 & 0.052 & 0.14 \\
\hline 8 & 0.213 & 0.964 & 0.953 & 0.986 & 0.163 & 0.795 & 0.879 \\
\hline 12 & 0.227 & 0.983 & 0.814 & 0.980 & 0.189 & 0.963 & 0.966 \\
\hline 16 & 0.895 & 0.849 & 0.204 & 0.826 & 0.029 & 0.983 & 0.918 \\
\hline
\end{tabular}

